NBER WORKING PAPER SERIES

\author{
HOW A FEE PER-UNIT \\ GARBAGE AFFECTS AGGREGATE \\ RECYCLING IN A MODEL WITH \\ HETEROGENEOUS HOUSEHOLDS
}

Thomas C. Kinnaman

Don Fullerton

Working Paper No. 4905

\author{
NATIONAL BUREAU OF ECONOMIC RESEARCH \\ 1050 Massachusetts Avenue \\ Cambridge, MA 02138 \\ October 1994
}

\begin{abstract}
We are grateful for helpful suggestions from Lans Bovenberg, Hilary Sigman, and other participants at the August 1994 Congress of the Intemational Institute of Public Finance in Cambridge, MA. We are also grateful for financial support from National Science Foundation Grant SBR-9413334. This paper is part of NBER's research program in Public Economics. Any opinions expressed are those of the authors and not those of the National Science Foundation or the National Bureau of Economic Research.
\end{abstract}

(c) 1994 by Thomas C. Kinnaman and Don Fullerton. All rights reserved. Short sections of text, not to exceed two paragraphs, may be quoted without explicit permission provided that full credit, including (c) notice, is given to the source. 


\title{
HOW A FEE PER-UNIT \\ GARBAGE AFFECTS AGGREGATE \\ RECYCLING IN A MODEL WITH \\ HETEROGENEOUS HOUSEHOLDS
}

\begin{abstract}
This paper develops a utility maximizing model of household choice among garbage disposal, recycling, and littering. The impact of a user fee for garbage collection is modelled for heterogeneous households with different preferences for recycling. The model explains (1) why some households participate in curbside recycling programs even in the absence of a user fee, (2) why other households do not participate, even in the presence of a user fee, and (3) why some households choose to litter when others do not. Household choices are aggregated to determine the effect of a user fee on the community-wide quantities of garbage, recycling, and litter. We show how an increase in the user fee can decrease aggregate recycling.
\end{abstract}

Thomas C. Kinnaman

Department of Economics

Bucknell University

Lewisburg, PA 17837
Don Fullerton

Department of Economics

University of Texas - Austin

Austin, TX 78712-1173

and NBER 


\section{Introduction}

Nearly 2000 communities have implemented user fees to finance garbage collection over the last five years, requiring households to pay for each bag of garbage presented for collection (Skumatz 1993). The revenue raised from these user fees has supplanted the use of general tax revenue to finance garbage collection and disposal costs. Casual evidence suggests that user fees are applied most predominantly in regions that have experienced large increases in disposal costs Benefits to the community include the social value of less garbage and more recycling. The costs include the social cost of additional litter and the value of resources used to administer the program. Both the benefits and costs depend on the waste removal choices of individual households within the community.

This paper develops a model of household choice among waste removal options, with diverse commodities and heterogeneous households. Each household compares the cost of curbside garbage collection, the cost of littering, and the cost of recycling for each type of waste material. A household that recycles compares the cost of free curbside recycling pickup with the cost of sending used materials directly to secondary markets (bypassing curbside pickup). Thus our model is general enough to encompass second-hand sales. A user fee for garbage collection is likely to affect the choice of each household over whether to discard, recycle, or litter.

Households within the community are assumed to differ over their income and preferences for recycling. The introduction of this type of heterogeneity in our model explains (1) why some households participate in a curbside recycling program even in the absence of a user fee, (2) why other households still do not participate in recycling programs even in the presence of a user fee for garbage collection, and (3) why some households choose to litter when others do not.

This model has two purposes. First, we wish to lay a theoretical foundation for future empirical work. Therefore we note where this theoretical model has empirical implications 
Second, we wish to think about how heterogeneous household behaviors affect aggregate garbage, recycling, and litter, and how these aggregate outcomes affect the costs and benefits to a community from the implementation of a user fee program. The model suggests that aggregate garbage will decrease with the value of the user fee. Aggregate litter increases with the user fee, but, perhaps surprisingly, aggregate recycling may decrease. The magnitude of these changes can vary across communities. These behavioral responses must be taken into account by any local policymaker considering a user fee for garbage collection. The consequence for empirical work, especially the use of a cross-section of communities with different user fees, is that each community's choice of user fee is not exogenous.

Sections 2 of this paper will introduce the model of household choice for methods of waste removal without the option to litter. The model is expanded to include the littering option in Section 3. Section 4 follows with a brief conclusion.

\section{A Model Of Household Disposal Choice}

Most models of household solid waste ignore the littering option. ${ }^{1}$ In an important study for the World Resources Institute, Repetto et al (1992) claim that any potential increases in dumping can be alleviated by simple measures. ${ }^{2}$ To characterize these existing studies, our initial model in this section ignores litter. Our analysis suggests that a model without the littering option is inadequate to explain how local governments set user fees.

'For example, Jenkins (1991), Copeland (1991), Sigman (1991), Dinan (1993), Morris and Holthausen (1994), Wertz (1976).

${ }^{2}$ They suggest locking dumpsters, vigorously publicizing and enforcing disposal rules in the initial months of the program, reporting households that put out no garbage, and requiring a onebag minimum. 


\subsection{Individual Behavior}

Assume that a community is comprised of heterogeneous households indexed by $i=$

$1, \ldots, \mathbf{I}$. Each household may engage in consumption of different goods indexed by $j=1, \ldots, \mathrm{J}$. To simplify notation throughout the paper, we use lower case letters to define variables for household

i. This convention allows us to suppress the $i$ index. Let $c_{j}$ denote the consumption of good $j$ by household $i$. The consumption of each good $j$ generates a certain quantity of waste material, denoted by $m_{j}$, which is assumed to be proportional to consumption:

$$
\mathrm{m}_{\mathrm{j}}=\mathrm{a}_{\mathrm{j}} \mathrm{c}_{\mathrm{j}}
$$

All waste material must be either collected as garbage (with amount $g_{j}$ ) or recycled (with amount $r_{\mathrm{j}}$ ). We add litter to the model in the next section. Since all matter must be removed from the household in one form or another, we have: ${ }^{3}$

$$
m_{j}=: g_{j}+r_{j}
$$

The household's total garbage and recycling are $g=\sum_{j} g_{j}$ and $r=\sum_{j} r_{j}$, respectively. We use upper case letters to denote amounts aggregated over all I households, so the town's total garbage is $G=\sum_{i} \sum_{j} g_{j}$.

Assume that household i's utility function is defined over its $\mathrm{J}$ consumption goods, the total amount of recycling it conducts ( $r$ ), and the total amount of garbage discarded by the

\footnotetext{
${ }^{3}$ Households could conceivably compost garbage or reduce the quantity of their garbage by demanding less packaging at stores. Since these amounts are relatively small, however, we concentrate here on the major components of the waste stream: garbage and recycling. Later we introduce burning or dumping $b_{j}$.
} 
community $(G)$

$$
u=u\left(c_{1}, c_{2}, \ldots, c_{J}, r, G\right)
$$

Using a subscript to denote a first derivative, we assume that households receive positive marginal utility from consumption $\left(u_{c j}>0\right)$, and possibly from recycling $\left(u_{r} \geq 0\right)$, but they dislike the odor. health problems, and environmental damage which may be associated with aggregate garbage amounts $\left(\mathrm{u}_{\mathrm{G}}<0\right)$. Since we assume a large number of households in the community, each household ignores the effect of its own contribution to aggregate garbage. Households differ over preferences for recycling: a household with a large value of $u_{r}$ enjoys recycling more than a household with a low value.

A potential problem with our specification is that individuals could buy more goods and generate more waste in order to enjoy more recycling. An alternative specification could assume disutility from generating waste (instead of utility from recycling). This alternative might have a different effect on total consumption, but it would have the same effect on the choice between garbage and recycling which is the focus of this paper. We cannot know why people recycle, exactly, but perhaps the act of recycling itself makes them feel they are doing something good for the environment.

Each household is endowed with $k$ units of time (or other resources) that can be supplied to a labor market to earn a wage $p^{k}$ (which can vary across households), or can be used to separate and store recyclable material. Let $\mathrm{k}^{\mathrm{c}}$ denote the amount of household time supplied to the labor market, and let $k^{k}$ denote the time devoted by household $i$ to the separation of recyclable materials. Therefore, we have: 


$$
k=k^{c}+k^{r}
$$

The amount of time devoted to separating and storing recyclable materials is assumed to be proportional to the amount of recycling conducted by the household:

$$
\mathbf{k}^{\mathrm{r}}=\text { or }
$$

We assume that $\sigma$ is the same for all households and all materials (but the value of that time varies with the wage rate, $\left.p^{k}\right){ }^{4}$

With no city program to collect recyclable material, a household must pay to transport the material to a recycling firm or resale market. Once there, the household either pays or receives a price for the transfer of the material. The total out-of-pocket expenses to each household that recycles the material of type $\mathrm{j}$ is, therefore, the transportation costs plus the cash payment to or from the firm. Denote this marginal cost paid by the household as $p_{j}^{r}$ per unit of material of type $j$ that is recycled. We assume that $p_{j}^{r}$ is particular to the type of material being recycled and can take on a positive or negative value. For example, the cost to the household of transporting and paying a firm to recycle toxic waste could be very high, while the household may be able to sell precious metals to a recycling firm ( $p_{j}^{r}$ could be negative). For used items sold on the second hand market, we interpret $p_{j}^{r}$ to include advertising costs.

Some materials may be collected from the curb as part of a curbside recycling program. The overall price paid by households to transport and recycle these materials will be zero. A curbside recycling program represents an implicit subsidy to the household of $s_{j}^{r}$ per unit of

"We might expect the effort expended to separate and store recyclable material would differ over households and material types, but making this more realistic assumption only serves to cloud the model and adds little to our results 
recycled material which offsets $p_{j}^{r}$ such that the overall cost $p_{j}^{r}-s_{j}^{r}=0$. The value of $s_{j}^{r}$ is zero for all materials not collected at the curb.

Assume that the local government charges a user fee per unit of garbage $t^{\mathrm{g}}$, regardless of the type of material. This fee is the household's only marginal cost of garbage disposal. The household may pay property taxes or a monthly fee, but, in the absence of a user fee for garbage collection, the price paid at the margin per bag of garbage is zero.

Household income $\left(p^{k} k-p^{k} k\right)$ can be used to purchase consumption goods at market prices $p_{j}^{c}$, to recycle material $j$ at unit cost $p_{j}^{r}$, to pay any user fee that might be levied on garbage, and to pay a lump sum tax $t^{L S}$. Therefore, the budget constraint facing the household is.

$$
\sum_{j} p_{j}^{c} c_{j}+t^{8} g+\sum_{j}\left(p_{j}^{r}-s_{j}^{r}\right) r_{j}+t^{L S}=p^{k} k-p^{k}(\sigma r)
$$

where $g=\sum_{j} g_{j}$ for household $i, s_{j}^{r}=p_{j}^{r}$ if the recyclable material $j$ is collected for free, and $s_{j}^{r}$ is zero for all other materials not collected for recycling.

Each household chooses the amount of each consumption good, and how to dispose of it, by maximizing utility (3) subject to (1), (2), and the budget constraint (6). A subset of the first order conditions from this maximization are:

$$
\begin{array}{ll}
d L / d g_{j}: \quad u_{c j} a_{j} \leq \lambda\left[p_{j}^{c}+t^{8}\right] & \text { for all } j \\
d L / d r_{j}: u_{c j} a_{j} \leq \lambda\left[p_{j}^{c}+\left(p_{j}^{r}-s_{j}\right)+o p^{k}\right]-u_{r} & \text { for all } j
\end{array}
$$

where $\lambda$ is the marginal utility of income to household $i$. Define $\lambda^{*}$ and $u_{r}^{*}$ to be the values of $\lambda$ and $u_{r}$ at the solution to (7). The household compares the cost of garbage collection $t^{8}$ to the overall marginal "cost" of recycling material $j$ - which is the money payment $\left(p_{j}^{r}-s_{j}\right)$ plus the 
value of time $\left(\sigma p^{k}\right)$ minus the value of marginal utility from recycling $\left(u_{p}^{*} / \lambda^{*}\right)$. These conditions could imply a set of corner solutions. If the overall marginal "cost" of recycling a newspaper is less than the cost of discarding it, then a household would be expected to recycle all of its newspaper, not just some portion of it." As long as $\mathrm{t}^{\mathrm{z}}$ does not exactly equal the full cost of recycling $\left(p_{j}^{r}-s_{j}^{p}\right)+\sigma p^{k}-u_{j}^{*} / \lambda^{*}$, for some good $j$, then household choice between waste removal options for that material is governed by:

$$
\begin{array}{lll}
g_{j}=m_{j} & \text { iff } & t^{8}<\left(p_{j}^{r}-s_{j}\right)+\sigma p^{k}-u_{j}^{*} / \lambda^{*} \\
r_{j}=m_{j} & \text { iff } & t^{2}>\left(p_{j}^{r}-s_{j}\right)+\sigma p^{k}-u_{j}^{*} / \lambda^{*}
\end{array}
$$

The household could choose an interior solution for a good $j$ in which it discards some portion $\left(g_{j}\right)$ and recycles some portion $\left(r_{j}\right)$ of the material, if $t^{B}=\left(p_{j}^{r}-s_{j}^{j}\right)+\sigma p^{k}-u_{j}^{*} / \lambda^{*}$. This equality will hold only for very few materials at the knife's edge where the cost of garbage collection exactly matches the overall marginal "cost" of recycling (including effects on time and utility) However, the household will never choose interior solutions for two goods with different marginal "cost". To see this, first remember that garbage and recycling are perfect substitutes in disposal $\left(m_{j}=g_{j}+r_{j}\right)$ and that different materials provide equal utility from recycling $\left(r=\sum_{j} r_{j}\right)$. Now suppose the household were using both garbage and recycling for two kinds of waste materials with different marginal "cost" of recycling. This situation cannot be an optimal solution because the household could switch one unit of the higher-recycling-cost waste from recycling to garbage, and switch one unit of the lower-recycling-cost waste from garbage to recycling, while consuming the same amount of each good, generating the same total garbage and recycling, and saving the difference in marginal cost. Such switches would continue until the household is

\footnotetext{
${ }^{5}$ This strong theoretical result is supported by casual observation. Households who recycle often devote space for virtually all quantities of certain materials, e.g. one bin for newspaper and another for aluminum cans.
} 
discarding all materials that meet condition (8a) and recycling all that meet (8b).

The same maximization provides first-order conditions for consumption, not shown, in which the "effective" price of consuming good $\mathrm{j}$ depends on its purchase price, the relative waste generated $\left(m_{j}=a_{j} c_{j}\right)$, and the cost of the chosen disposal method for that good. We thus capture the possibility that a garbage fee can discourage consumption of waste-intensive commodities.

To focus on disposal choices, in Figure 1, we assume that all types of materials can be ranked in a descending order according to the cost of recycling $\left(\mathrm{p}_{\mathrm{j}}^{\mathrm{j}}\right)$. For example, toxic waste would be ranked first and precious metals last. The overall schedule of recycling costs is labeled $P^{r}$ in Figure 1, with material types ranked from highest cost to lowest cost from left to right. Discrete goods $(j=1, \ldots, J)$ would generate a step function, but we show a continuous $\mathrm{pr}^{\mathrm{r}}$ schedule for ease of exposition. This schedule does not have to be linear or even differentiable, it only has to be non-increasing.

The first order conditions indicate that the overall marginal "cost" to the household of recycling includes the value of resources devoted to separating and storing the material of type $j$, $a p_{k}$ per unit, regardless of the type of material being recycled. The addition of this cost introduces another curve in Figure 1 higher than $\mathrm{P}^{r}$ but parallel, labeled $\mathrm{P}^{x}+\sigma \mathrm{p}^{k}$. The overall marginal "cost" of recycling also includes the value of the marginal utility gained by household $i$ from its recycling efforts, $u_{r}^{*} / \lambda^{*}$. We assume that the value of the marginal utility of recycling is also constant across materials and serves to introduce the lower overall marginal "cost" function parallel to the other curves, labeled $\mathrm{MC}^{\mathrm{r}}$ in Figure 1. The magnitude of the total difference between $\mathrm{P}^{r}$ and $\mathrm{MC}^{r}$ is unique to household $\mathrm{i}$ because each household has a different value of $u_{r}^{*} / \lambda^{*}$. Let $\rho=\sigma p^{k}-u_{r}^{*} / \lambda^{*}$ be the additional cost (or benefit) of recycling beyond $p_{j}^{r}$. Therefore, the overall marginal "cost" of recycling to household $\mathrm{i}$ is equal to $\mathrm{MC}^{\mathrm{r}}=\mathrm{P}^{\mathrm{r}}+\rho$ per unit recycled. This marginal cost schedule allows us to illustrate the amounts of total garbage and 
recycling chosen by the household.

According to the first-order conditions, household i can be expected to remove material $\mathrm{j}$ by using the lowest cost alternative. Therefore, we seek the lower envelope of marginal waste removal costs across all materials. If the per-unit cost to discard garbage is zero, Figure 1 indicates that household $i$ will discard all materials ranked to the left of point $g$ (where the cost to discard garbage is less than the cost to recycle) and will recycle the remaining materials ranked to the right of point $\mathrm{g}$ (and to the left of point $\mathrm{m}$ ). ${ }^{6}$ Without a curbside collection program for recyclable materials, the household must transport and exchange the materials themselves. The amounts of garbage and recycling by each household will depend on where that household's unique $\mathrm{MC}^{\mathrm{r}}$ curve intersects the horizontal axis

Figure 1 can also be used to indicate how much garbage and recycling will be produced ty a household when a user fee for garbage collection is implemented. A user fee of $\mathbf{t}^{\mathrm{g}^{\prime}}$ per bag causes household $i$ to decrease the amount of garbage from $g$ to $g^{\prime}$ and to increase the material it recycles from $(m-g)$ to $(m-g)$. The magnitudes of these changes depend on the slope of the $\mathrm{MC}^{\mathrm{r}}$ curve through point $\mathrm{g}$. The flatter is $\mathrm{MC}^{\mathrm{r}}$, the cheaper it is to recycle additional materials

The implementation of a curbside recycling program also affects the waste disposal choices of households. Assume that the local government has agreed to collect, transport, and recycle certain materials at no cost to the household (an implicit subsidy of $s_{j}^{r}=p_{j}^{r}$ ). Therefore, the overall marginal "cost" of recycling materials that are collected from the curb is only $\rho$ (the extra time $o p^{k}$ minus the value of marginal utility). In the absence of a user fee for garbage collection $\left(t^{8}=0\right)$, only households that like recycling $(\rho<0)$ will participate in free curbside recycling. All households with $\rho>0$ will not participate. All households might still recycle,

${ }^{6}$ The household is indifferent between discarding and recycling the material ranked exactly at point $\mathrm{g}$ (at the knife's edge). If a discrete amount of some material has $\mathrm{t}^{\mathrm{g}}=\mathrm{MC}$, the household could employ positive quantities of both methods to remove this material 
directly to secondary markets, if they receive a price such that the net cost $\mathrm{MC}^{r}$ is less than the cost of any alternative (either 0 for garbage, or $\rho<0$ for those who curbside recycle).

Figure 2 illustrates the new recycling cost schedule to the household when materials ranked to the right of point a are collected for free. The government is not willing to collect materials ranked to the left of point a, perhaps because it costs too much to recycle these materials.' The $\mathrm{P}^{r}$ schedule drops down to zero at point a for all materials that are collected, and it may fall below zero later for goods that can be sold on secondary markets. The household must still devote time to separating and storing any material it recycles, and may receive utility from doing so. Therefore, the overall marginal "cost" to the household will be represented by an $\mathrm{MC}^{r}$ curve that is flat over the range of materials that are collected for recycling.

The recycling cost function of two households in the same community, but with different preferences for recycling, are labeled $M C_{1}^{r}$ and $M C_{2}^{r}$ in Figure 2. The household with $M C_{2}^{r}$ has greater preferences for recycling than the household facing $M C_{1}^{r}$. Since $M C_{2}^{r}$ lies below the $\mathrm{P}^{r}$ schedule for this household, it must have $\rho_{2}<0$. For the household facing $M C_{1}^{r}, \rho_{1}>0$

The household with $\mathrm{MC}_{2}^{r}$ (and all other households with $\rho<0$ ) will participate in the curbside recycling program in the absence of a user fee for garbage collection, since the overall marginal "cost" of recycling these items is less than zero. To see this, look for the lower envelope of marginal costs in Figure 2. Household 2 discards all materials ranked to the left of $g_{2}$ (point a), recycles all materials ranked between $g_{2}$ and $d$ at the curb, and sells all materials ranked to the right of $d$ in secondary markets (where $p_{j}^{r}<0$ so they get paid for those materials). An increase in the user fee $t^{8}$ above zero would not increase recycling for these households.

The household represented by $\mathrm{MC}_{1}^{r}$ (and all other households with $\rho>0$ ) will not recycle

\footnotetext{
'We assume that the government's decision over which materials to collect is exogenous to the model.
} 
at the curb at all as long as the cost to discard garbage is $t^{8}=0$. This household discards all materials ranked to the left of $g_{1}$ (where $t^{8}=0$ is less than $M C_{1}^{r}$ ) and sells material ranked to the right of $g_{3}$ in secondary markets. In order to encourage these households to recycle at the curb, the government must implement a garbage fee.

If $t^{8}>\rho_{1}$ is levied on each bag of garbage collected, the household with $M C_{2}^{r}$ will not change its disposal behavior. It will still recycle materials ranked between $g_{2}$ and $d$ at the curb. The household represented by $\mathrm{MC}_{1}^{r}$ now has the incentive to participate in the curbside recycling program. It discards all materials ranked to the left of point a, presents material ranked between a and $\mathrm{d}$ at the curb for recycling (since $\mathrm{MC}^{\mathrm{r}}<\mathrm{t}^{\mathrm{g}}$ for those materials), and sells all material ranked to the right of $d$ in secondary markets. As indicated by equation (8b), $t^{8}$ must be greater than $\rho$ to induce these households to choose to recycle these materials ranked between a and $d$ at the curb. Larger values of the user fee would be needed to encourage households with even lower preferences for recycling (higher $\rho$ ) to recycle at the curb. ${ }^{8}$

\subsection{Aggregate Behavior}

The point of the theory is to explain how a user fee for garbage collection affects the aggregate amounts of garbage and recycling produced by a community. These aggregate curves are obtained by summing horizontally across the garbage and recycling quantities produced by all households in the community, for any possible value of a user fee. Aggregate curves for two different communities are illustrated in Figure 3.

Assume that both communities have the same amount of aggregate material $\left(M=\sum_{i} \sum_{j} m_{j}\right)$

\footnotetext{
${ }^{8} \mathrm{~A}$ mandatory recycling law provides incentives similar to those of a user fee. For those materials that households are required to recycle, the expected cost of discarding increases as the expected fine for non-compliance increases or as the probability of getting caught increases. Households with very high values of $\rho$ would require a high penalty or greater enforcement to convince them to recycle.
} 
to discard and do not have curbside recycling programs. Aggregate demand for recycling in community 1 is the horizontal distance from point $M$ leftward to the curve labelled $D_{1}^{R}$, and aggregate garbage is the rest of $M$. In the absence of a user fee for garbage collection, for example, households in community 1 discard $G_{1}$ in a landfill and recycle $M-G_{1}$. This community will reduce its garbage to $G_{1}^{*}$ and increase its recycling to $\left(M-G_{1}^{\prime}\right)$ once the government implements a user fee of $\mathrm{t}^{\mathrm{s}}$. These changes arise because all households in the community choose to recycle more materials once a user fee is implemented (as in Figure 1).

The $D_{2}^{R}$ function determines the aggregate quantity of garbage and recycling produced by community 2. At any value of the user fee, this community recycles a greater quantity of material than the first community. If a user fee with value $t^{g}$ is levied, for example, community 2 discards $\mathrm{G}_{2}^{\prime}$ and recycles $\left(\mathrm{M}-\mathrm{G}_{2}\right.$ ). Community 2 could be comprised of more households that have strong preferences for recycling.

Empirical observation indicates that some local governments have chosen to implement user fees for garbage collection while most others have not. We assume that a local government will implement a user fee if the benefits of doing so out-weigh the costs. Since households dislike the aggregate quantity of garbage $\left(\mathrm{u}_{\mathrm{G}}<0\right)$, important benefits are the reduction in garbage and increase in recycling that result from the user fee. Since households in this model engage in no dumping, the only cost is the value of resources used to administer the user fee program.

As drawn in Figure 3, the change in garbage and recycling quantities resulting from the implementation of a user fee is greater for community 1 than for community 2 . The town of those with high preferences for recycling (community 2) does not necessarily experience a large increase in aggregate recycling due to a user fee. Households in community 2 may be recycling in large quantities before the user fee, leaving little room for additional recycling. Therefore the benefits of implementing a user fee may be greater for community 1 than for community 2 . Ceteris 
paribus, we expect communities with flatter $D^{R}$ schedules (like $D_{1}^{R}$ ) to be more likely to implement a user fee.

Why is community 1 more conducive to the implementation of a user fee for garbage collection than community 2 ? Our model suggests that community 1 must be comprised of many households that increase their recycling amounts following the implementation of a user fee. These large increases would result if the $\mathrm{MC}^{r}$ schedule in Figure 1 is relatively flat near the horizontal axis, and if many households in the community do not participate in the curbside recycling program before the user fee. A flat $\mathrm{MC}^{r}$ schedule indicates that more materials can be recycled at a low additional cost to the household. In the presence of a curbside recycling program, for example, the overall marginal "cost" of recycling is flat across those materials collected at the curb. This serves to flatten the aggregate recycling schedule. Therefore, communities with curbside recycling may be more likely to implement a user fee

Suppose the value of the user fee does not affect administrative costs such as advertising the program, printing the stickers, and enforcing the law. Since the benefits of implementing the user fee progran increase with the value of the user fee, and the costs do not, this simple model without a litter option suggests that governments would be likely to levy a very high user fee.? For example, the government in community 1 could levy a user fee with a value of $t_{\text {max }}^{\mathrm{g}}$ and then collect no garbage. All materials would be recycled. Therefore, the model suggests that all governments would either (1) not implement a user fee, if the administrative cost is greater than the benefit of having no garbage, or (2) charge at least $t^{8}{ }_{\max }$ for each bag of garbage, if the benefits of no garbage exceed the administrative cost of the user fee program

Casual observations in the U.S. reject this theoretical implication. Only 2000 communities

\footnotetext{
${ }^{9} \mathrm{~A}$ user fee may change the relative price of a consumption good that is more waste intensive than others. Therefore, another cost or benefit of implementing a user fee is this effect on consumption
} 
across the U.S. have implemented user fees for garbage collection. Most of these fees are moderate, like $\$ 80$ per bag. One explanation for the failure of this model to explain government behavior could be that governments are concerned with the amount of illegal dumping that would arise following the implementation of a user fee. A more appropriate model would include illegal dumping as a third removal option for households. We now proceed to develop such a model.

\section{The Model With a Littering Option}

Several recent models of household solid waste behavior have considered the littering option. Kennedy and Laplante (1994) solve for the optimal user fee given the option to litter, but they do not consider materials with different recycling costs. Fullerton and Kinnaman (forthcoming) allow the price of recycling to vary across goods, but treat all households as identical. Sullivan (1987) and Dobbs (1991) also allow for litter in their models. We present the only model to allow heterogeneous households to choose among three removal methods for diverse types of goods.

\subsection{Individual Behavior}

Assume that households have the option to burn, dump, or litter garbage:

$$
m_{j}=g_{j}+r_{j}+b_{j}
$$

where $b_{j}$ is the amount of burning of material $j$ conducted by household i. Also, assume that all households dislike the aggregate amount of burning or littering that occurs in their community:

$$
u=u\left(c_{1}, \ldots, c_{J}, r, G, B\right)
$$


where $B=\sum_{i} \sum_{j} b_{j}, u_{B}<0$, and all other variables are defined as above.

No market or price exists for the littering or burning of garbage, but we assume that the household must pay a fixed cost $f$ if it engages in such practice. This fixed cost could include, for example, the cost of finding a suitable dump site, the fixed portion of the cost of traveling to the dumpsite, the psychic cost of breaking a local ordinance, and the risk of a fine. In other words, dumping two bags is not twice as costly as dumping one bag, in terms of transport cost, the risk of getting caught, and feeling bad about this antisocial behavior. Later we address the possibility that fixed costs arise in recycling.

Littering also involves a marginal cost equal to the value of household time $\left(\mathrm{k}^{\mathrm{b}}\right)$ devoted to burning each unit of waste material or hauling it to the illegal dump site. Assume that the amount of time devoted to hauling such bags is proportional to the amount of burning or littering conducted by the household:

$$
\mathrm{k}^{\mathrm{b}}=\delta \mathrm{b}
$$

where $b=\sum b_{j}$. Then the new budget constra.nt facing the household is:

$$
\begin{array}{cc}
\sum_{j} p_{j}^{c} c_{j}+t^{8} g+\sum_{j}\left(p_{j}^{r}-s_{j}\right) r_{j}+t^{L S}=p^{k}(k-\sigma r) & \text { if } b=0 \\
\sum_{j} p_{j}^{c} c_{j}+t^{8} g+\sum_{j}\left(p_{j}^{r}-s_{j}\right) r_{j}+f+t^{l s}= & \\
p^{k}(k-\delta b-o r) . & \text { if } b>0 .
\end{array}
$$

Household i maximizes utility (10) subject to (1), (9), and the budget constraint (12) by choosing the amounts of consumption, garbage, recycling, and litter. First order conditions for disposal are: 


$$
\begin{array}{lll}
d L / d g_{j}: & u_{c j} a_{j} \leq \lambda\left[p_{j}^{c}+t^{8}\right] & \text { for all } j \\
d L / d r_{j}: & u_{c j} a_{j} \leq \lambda\left[p_{j}^{c}+\left(p_{j}^{r}-s_{j}\right)+\sigma p^{k}\right]-u_{r} & \text { for all } j \\
d L / d b_{j}: & u_{c j} a_{j} \leq \lambda\left[p_{j}^{c}+\delta p^{k}\right] & \text { for all } j
\end{array}
$$

where $\lambda$ is still the marginal utility of income to household i. Again, these results imply a set of comer solutions if the values of the right-hand sides of (13) are not equal to each other. If the household engages in no littering $(b=0)$ then household behavior is described by $(8 a)$ and $(8 b)$ With some illegal dumping (b>0), choice over methods of removing the waste material of type $j$ is determined by:

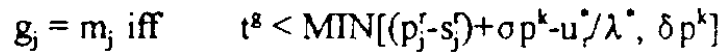

$$
\begin{aligned}
& r_{j}=m_{j} \text { iff } \quad\left(p_{j}^{r}-s_{j}^{r}\right)+o p^{k}-u_{i}^{*} / \lambda^{*}<\operatorname{MIN}\left[t^{8}, \delta p^{k}\right] \\
& b_{j}=m_{j} \text { iff } \quad \delta p^{k}<\operatorname{MIN}\left[t^{8},\left(p_{j}^{r}-s_{j}^{r}\right)+o p^{k}-u_{r}^{*} / \lambda^{*}\right]
\end{aligned}
$$

where $\lambda^{*}$ and $u_{r}^{*}$ are the values of $\lambda$ and $u_{r}$ evaluated at the maximum.

Household $\mathrm{i}$ will again choose to remove material $\mathrm{j}$ using the lowest cost alternative (where the "cost" of recycling includes effects on time and utility). For most materials, households are predicted to use only one method of removal.

\subsubsection{With No Curbside Recycling}

When will a household pay the fixed cost associated with littering garbage? In the absence of a curbside recycling program, the answer depends on the value of the user fee and the schedule of recycling costs. Figure 4 a illustrates the conditions that create the incentive for a household to pay the fixed costs ( $f$ ) and litter garbage. Assume, again, that we can order materials according to 
the overall marginal "cost" of recycling, $\mathrm{MC}^{r}$, which includes the cost of household time spent separating and storing material and the value of any utility received from doing so. The average cost $\left(\mathrm{AC}^{\mathrm{b}}\right)$ and the marginal cost $\left(\mathrm{MC}^{\mathrm{b}}\right)$ of burning or littering are also shown in Figure $4 \mathrm{a}$. The quantity of litter is measured from the origin rightward, and the quantity of recycling is still measured from $m$ leftward, so the quantity of garbage is the amount in between.

If we start with a zero fee for garbage collection, the household will litter nothing, will discard all materials ranked to the left of $g_{0}$, and will supply the remaining materials $\left(m-g_{0}\right)$ directly to secondary markets. These results are again determined by looking for the lower envelope of disposal costs: the household uses $t^{\mathrm{B}}=0$ until $\mathrm{g}_{o}$, and then uses $\mathrm{MC}^{\mathrm{r}}<0$ ). If a user fee for garbage collection is implemented, we can find the fee $\bar{t}^{g}$ such that the household is indifferent between paying the fee for garbage vs. paying the fixed costs $f$ and then dumping waste illegally. If $\mathbf{t}^{\mathrm{B}}$ is below $\overline{\mathrm{t}}^{\mathrm{B}}$, then the household will still not litter because the fixed cost of littering is more than the money saved by not paying the user fee. If a user fee of $\bar{t}^{\mathrm{B}}$ is charged for each bag of garbage, the household is inditierent between (1) putting into garbage all materials ranked to the left of $g_{1}$ and supplying all other materials to secondary markets, and (2) dumping all materials ranked to the left of $b_{f}$ and supplying the remaining materials to secondary markets. The threshold value of the user fee $\left(\mathrm{t}^{\mathrm{B}}\right)$ is found where the total cost of option (1), denoted by the trapezoidal area $\bar{t}^{8}, a, g_{0}, 0$ in Figure $4 a$ (the cost of discarding $g_{4}$ plus the cost of recycling $g_{0}-g_{1}$ ), is equal to the total cost of option (2), which is $A C_{f}^{b}, d, c, g_{o}, 0$ (the cost of burning or dumping $b_{f}$ and recycling $g_{o}-b_{f}$ ). The household would choose the second option for any user fee with value greater than $\bar{t}^{\mathrm{B}}$.

The information contained in Figure $4 \mathrm{a}$ can be captured in a another manner using Figures $4 b, 4 c$, and $4 d$. Figure $4 b$ maps the demand curve for garbage as a function of the user fee. As stated above, the household decreases its quantity demanded for garbage collection (and increases 
recycling) as the price of garbage increases to $\bar{t}^{2}$. Once the price of garbage exceeds this threshold value, the quantity demanded for garbage collection falls to zero. Figure $4 \mathrm{c}$ maps the cross-price relationship between the price of garbage and the quantity of recycling. Household recycling increases with larger values of the user fee over the interval between zero and $\bar{t}^{\mathrm{g}}$. At this point, recycling decreases as the household begins to litter garbage. Once the fixed costs of littering are paid, the marginal cost of littering items ranked from $b_{f}$ leftward is $\delta p^{k}$, which is less than the marginal cost of recycling them. Household recycling efforts are unresponsive to all values of the user fee that are greater than $\bar{t}^{g}$. Figure $4 d$ illustrates the effect of the user fee on the quantity of burning or dumping litter. No littering is conducted below the threshold value of the user fee, but the household litters $b_{f}$ for all values of the user fee that are greater than $\bar{t}^{g}$ Several points arise from this simple model. First, the household would never simultaneously engage in positive quantities of littering $b$ and discarding garbage $g$. The household uses garbage and recycling at low values of the user fee, and only uses dumping and recycling at high values. Second, the househc $l_{\imath}$ ' will never recycle more than $\left(m-g_{t}\right)$ for any value of the user fee. Third, the household recycles the same materials when the value of the user fee is equal to $\delta \mathrm{p}^{k}$ as it would for all values of the user fee that are greater than $\bar{t}^{\mathrm{B}}$. Therefore, a very high user fee may not be optimal. In fact, free garbage collection may be optimal if (1) the administrative cost of operating a user fee program is high, (2) $\bar{t}^{B}$ is relatively low, and (3) $u_{B}$ is large in absolute value.

Recall that $\rho$ (which is equal to $\sigma p^{k}-u_{r}^{*} / \lambda^{*}$ ) is the additional cost (or benefit) of recycling beyond $p_{j}^{r}$. The values of $g_{0}, b_{f}, g_{1}$, and $\bar{t}^{8}$ in Figure $4 a$ are determined by the value of $\rho$ and are, therefore, unique to each household. The values of $g_{o}, b_{f}$, and $g_{1}$ decrease as the value of $\rho$ decreases. Households with high preferences for recycling will recycle more, discard less, and litter less than households with low preferences for recycling. The threshold value of the user fee 
$\left(\mathrm{t}^{3}\right)$ increases as $\rho$ decreases. Therefore, households that have higher preferences for recycling wait for a higher value of the user fee before they are induced to litter their garbage. A decrease in the value of $\rho$ will also serve to shift the curves in Figure $4 b$ and $4 d$ to the left and shift the curve in Figure $4 \mathrm{c}$ to the right, while at the same time raising the threshold value of the user fee.

\subsubsection{With Free Recycling at the Curb}

How will the implementation of a curbside recycling program influence household response to a user fee for garbage collection? Assume that the city is willing to collect materials ranked between point $\mathrm{a}$ and point $\mathrm{m}$ in Figure 5a, at no monetary cost to the household. Notice that households would still sell the more valuable material toward the right, to a secondary market rather than put to the curb for city collection. A household will respond to a user fee in one of four ways, according to its value of $\rho$. Table 1 summarizes the main features of each category of households. Preferences for recycling increase (so the value of $\rho$ decreases) for higher-numbered categories. The first category of households will never recycle at the curb, regardless of the value of the user fee. The second and third categories of households will recycle at the curb for a certain range of user fee, but will not recycle for values outside this range. The third category of households will still recycle at the curb even when it engages in littering. The fourth category of households will recycle at the curb for all values of the user fee.

The first category of households have the lowest preference for recycling, so the value of $\rho$ is very high. Therefore, the overall marginal "cost" to recycle, denoted by $\mathrm{MC}^{t}$ in Figure 5a, is very high. In the absence of a user fee, the household discards $g_{0}$ at no cost and sends $\left(m-g_{0}\right)$ to a secondary market. This household will sell more material in secondary markets as the value of the user fee increases from zero, but will still not participate in a curbside recycling program. To try to induce these households to participate in the curbside recycling program, a user fee 
would have to be implemented with a value greater than $\rho$. However, any value of the user fee which is greater than $\bar{t}^{8}$ would cause this household to pay the fixed costs and litter all materials ranked to the left of $b_{f}$. Since $\rho>\bar{t}^{-}$, this household will never recycle at the curb.

Figures $5 b, 5 c$, and $5 d$ summarize the relationships between the value of the user fee and the quantities of garbage $(\mathrm{g})$, recycling $(\mathrm{r})$, and burning (b). A small user fee will induce this kind of household to sell more materials in secondary markets, but any user fee greater than $\bar{t}^{\mathrm{B}}$ will induce this household to litter.

The second category of households have some taste for recycling, but the overall marginal "cost" of recycling material collected at the curb $(\rho)$ is greater than the marginal cost of littering $\left(\delta p^{k}\right)$. This household will only recycle at the curb for specific values of the user fee. The household will instead discard these materials if the user fee is too low $\left(t^{8}<\rho\right)$ or litter them if the user fee is too high $\left(t^{8}>\bar{t}^{8}\right)$.

Figure $6 a$ illustrates the behavior of thic sategory of households. In the absence of a user fee, this category will put into garbage all materials ranked to the left of $g_{0}$ and will sell the remaining materials in secondary markets. As the value of the user fee increases from zero, the household will gradually discard less material and recycle more. It will recycle at the curb for values of the user fee slightly greater than $\rho$. At $\bar{t}^{8}$, the household is indifferent between (1) discarding all materials ranked to the left of $g_{t}$ and recycling the rest (including materials $g_{0}{ }^{-} g_{t}$ collected at the curb), and (2) littering all materials ranked to the left of $b_{f}$ and sending ( $\left.m-b_{f}\right)$ to secondary markets. The total cost of method $l$ is the area $\left(\bar{t}^{8}, a, h, c, g_{0}, 0\right)$, while that of method 2 is $\left(A C_{f}^{b}, d, e, g_{0}, 0\right)$. The threshold value of the user fee $\left(t^{z}\right)$ is found where these two areas are equal. The household chooses to litter $b_{f}$ for all values of $t^{8}$ greater than $\bar{t}^{8}$.

These results are also summarized in Figures $6 \mathrm{~b}, 6 \mathrm{c}$, and $6 \mathrm{~d}$, where quantities of garbage, recycling, and litter are mapped over all positive values of the user fee. Figure $6 \mathrm{~b}$ shows that, as 
the value of the user fee increases from zero, households in this category gradually reduce the quantity of garbage. As the user fee increases above $\rho$, the household sharply reduces its garbage and begins to recycle at the curb. Once the user fee rises above $\bar{t}^{g}$, the household stops discarding garbage, and, as Figure $6 \mathrm{~d}$ illustrates, begins to litter. This response of recycling to a user fee is somewhat surprising. The household participates in curbside recycling for values of the user fee slightly greater than $\rho$, but it abandons its curbside recycling efforts once the user fee exceeds $\bar{t}^{8}$. At this high fee, the household has the incentive to pay the fixed cost $f$ associated with dumping. Since the marginal cost of dumping materials $\left(\delta \mathrm{p}^{k}\right)$ is lower than the overall marginal "cost" of recycling them at the curb ( $\rho)$, the household will litter these recyclable materials as well.

Preferences towards recycling increase for households in the third category. The only difference between this category and the second is that the overall marginal "cost" of recycling $(\rho)$ is now less than the marginal cost of littering those materials $\left(\delta \mathrm{p}^{\mathrm{k}}\right)$. However, the overall marginal "cost" of recycling these materials is still greater than zero. Therefore, households in this category are not expected to recycle at the curb in the absence of a user fee for garbage collection. See Figure 7a.

With no user fee for garbage collection, households in this category discard all materials ranked to the left of $g_{o}$ and sell the rest directly to secondary markets. This household only participates in curbside recycling for values of the user fee greater than $\rho$. More specifically, the household will discard all materials ranked to the left of $g_{c}$, will recycle at the curb all materials $\mathrm{g}_{-}-\mathrm{g}_{\mathrm{r}}$, and will sell the remaining $\mathrm{m}-\mathrm{g}_{\mathrm{r}}$ materials in secondary markets. The household may even send materials ranked to the left of $g_{1}$ to secondary markets if the value of the user fee exceeds 
the $\mathrm{MC}^{\mathrm{r}}$ at $\mathrm{g}^{\mathrm{t}}$ (call it $\mathrm{MC}_{\mathrm{t}}$ ) ${ }^{10}$ These materials ranked to the left of $\mathrm{g}$ are not collected for free by the city. If the value of the user fee exceeds the threshold value of $\bar{t}^{\mathrm{g}}$, the household begins to litter. However, contrary to households in category 2 , households in category 3 will only litter materials ranked to the left of $g_{c}$ (once they have paid the fixed costs of dumping), and they will still participate in the curbside recycling program for materials ranked between $g$. and $g$. These households still recycle at the curb for very high values of $t^{8}$ because the marginal cost of dumping those materials $\left(\delta p^{k}\right)$ is greater than the overall marginal "cost" of recycling them ( $p$ ).

The behavior of households in this category is also summarized in Figures $7 \mathrm{~b}, 7 \mathrm{c}$, and $7 \mathrm{~d}$ The only difference between these figures and those presented for households in category 2 is

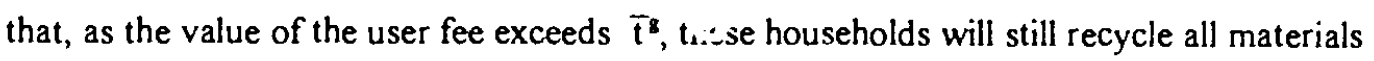
collected at the curb instead of littering them.

Households in category 4 have $\rho<0$ and thus will recycle at the curb even in the absence of a user fee. The logic can be seen in Figure 8a. The overall marginal "cost" to recycle materials collected at the curb ( $\rho$ ) is less than zero, the marginal cost of discarding garbage in the absence of a user fee. The household discards all materials to the left of $g_{0}$ and participates in curbside recycling in the absence of a user fee. Therefore, the implementation of a user fee for garbage collection will have no impact on this household's curbside recycling level until the value of the user fee is very large. User fees greater than $\mathrm{MC}^{r}$ at point $\mathrm{g}_{0}$ (call it $\mathrm{MC}_{0}^{r}$ ) will induce this household to send more materials ranked to the left of $g$ to secondary markets (paying $p^{r}>0$ ). ${ }^{\prime \prime}$ However, if the value of the user fee exceeds $\bar{t}^{B}$, the household begins to litter all material ranked

\footnotetext{
${ }^{10}$ This result depends on whether the $\mathrm{MC}^{r}$ function and the $\mathrm{AC}^{\mathrm{b}}$ function cross above or below point $\mathrm{MC}_{\mathrm{t}}^{\mathrm{r}}$. Figure $7 \mathrm{a}$ is drawn with those functions crossing above $\mathrm{MC}_{\mathrm{t}}^{\mathrm{r}}$. If these lines cross below this point, no additional recycling will take place.

${ }^{11}$ As described in the preceding footnote, this result depends on whether the $\mathrm{MC}^{\mathrm{r}}$ and $\mathrm{AC}^{\mathrm{b}}$ cross at a point above or below $\mathrm{MC}_{0}^{\text {? }}$.
} 
to the left of $g_{0}$ (at marginal cost $\delta p^{k}$ ) and recycle the rest.

Figures $8 \mathrm{~b}, 8 \mathrm{c}$, and $8 \mathrm{~d}$ summarize these results. Notice in Figure $8 \mathrm{c}$ that the amount of recycling conducted by these households is fairly unresponsive to price. In fact, the only major change in waste removal methods attributed to a change in the user fee is a switch from discarding garbage (g) to burning or littering (b). This switch occurs for values of the Lser fee greater than

$\bar{t}^{8}$. This result suggests that garbage fees would have little success in increasing the recycling levels of households who have rather strong preferences for recycling. These households already participate in the curbside recycling program in the absence of a user fee, leaving little room to increase their recycling quantities following the implementation of the user fee. ${ }^{12}$

\subsection{Aggregate Behavior}

The community's demand schedule for garbage collection can be derived by adding horizontally the amounts of garbage thrown out by all households in the community, at each value of the user fee. Individual garbage quantities with curbside recycling are depicted in Figures $5 \mathrm{~b}$ through $8 \mathrm{~b}$, where all types of households either reduce or leave unchanged their garbage quantities with increases in the value of the user fee. A higher user fee never increases the quantity of garbage. Therefore, aggregate garbage never increases with the user fee.

Similarly, Figures (5d) through (8d) illustrate that increasing values of the user fee either increase or leave unchanged amounts of litter for all households. Therefore, the aggregation of household litter must either increase or remain unchanged with higher values of the user fee. Aggregate litter will never decrease.

The same story cannot be told for aggregate recycling levels. One might expect that

\footnotetext{
${ }^{12} \mathrm{~A}$ possible fifth category of households will never litter garbage. The overall marginal "cost" of recycling even the most expensive items (the whole $\mathrm{MC}^{r}$ schedule) is less than the cost of burning or littering (the $\mathrm{AC}^{b}$ schedule)
} 
aggregate recycling would increase with higher values of the user fee, and this result certainly holds for some households over some ranges of the user fee. However, Figures (5c) through (8c) indicate that all categories of households reduce recycling over some range of the user fee Different households will decrease recycling by different amounts, and over different ranges of $t^{\mathrm{g}}$. Therefore, the horizontal aggregation of recycling across all households could either rise or fall with increasing values of the user fee.

The logic is a bit different for each category of households, but increases in $t^{8}$ will eventually induce all households to pay the fixed cost and begin to litter waste material. Once these fixed costs are paid, the household may find the marginal cost of dumping $\left(\delta p^{k}\right)$ to be less than the overall marginal "cost" of recycling ( $: 2)$. At this point, a higher value of $t^{z}$ induces less recycling.

The relationships between the user fee and these aggregate amounts are illustrated in Figure 9 for two specific communities. The function for community 1 (call it $D_{1}^{R}$ ) is drawn so that aggregate recycling (measured from the point $M$ leftward) rises with the user fee. The litter function for community 1 (call it $D_{1}^{B}$ ) reflects the fact that some households, perhaps in category 1, litter garbage even at very low values of the user fee. As the user fee increases from zero, more households are predicted to pay the fixed cost associated with littering and contribute to aggregate litter.

If no user fee is charged for garbage, the community with recycling function $D_{1}^{R}$ and littering function $D_{1}^{B}$ litters an amount $B_{1}=0$, recycles $M-G_{1}$, and discards $G_{1}$. As long as the marginal cost of littering is positive and the marginal cost to discard garbage is zero, then all communities experience no litter in the absence of a user fee. Once a user fee of $t^{g^{\prime}}$ is levied, the amount of litter increases to $B_{1}^{\prime}$, the amount of recycling increases to $M-G_{1}^{\prime}$, and the amount of garbage decreases to $G_{1}^{\prime}-B_{1}^{\prime}$. 
These functions for a second community are denoted by $D_{2}^{R}$ and $D_{2}^{B}$. With user fee $t^{\mathrm{B}^{1}}$, community 2 increases litter from $B_{2}$ to $B_{2}^{\prime}$, increases recycling from $M-G_{2}$ to $M-G_{2}^{\prime}$ and reduces the level of garbage from $G_{2}-B_{2}$ to $G_{2}^{-}-B_{2}$. Notice that the increase in litter is smaller than experienced by community 1 . As drawn, the change in recycling for community 2 is larger than for community 1 . Therefore, community 2 may realize greater benefits and lower costs from the implementation of a user fee. ${ }^{13}$

\section{Implications and Conclusion}

This paper has contributed to the literature on user fees for garbage collection in several ways. We introduced heterogeneity into a model of household choice over garbage removal methods. This model explained (1) why some households participate in curbside recycling programs in the absence of a user fee, (2) why other households do not recycle at the curb even in the presence of a user fee, and (3) why some households choose to litter garbage when others do not. We aggregated diverse households in each community to provide a prediction that a user fee will never increase garbage, and will never decrease illicit burning or dumping. At some point, however, the garbage fee becomes high enough to induce some people to pay the fixed cost of dumping and thus to switch away from recycling. As a consequence, the garbage fee might decrease aggregate recycling.

The model is general enough to encompass fixed costs for recycling instead of for dumping. Individuals and recycling firms may incur search and transport costs that do not vary with the amount recycled. If so, the same model could be employed to show that a rising garbage fee would generate monotonic decreases in garbage and monotonic increases in recycling. At

\footnotetext{
${ }^{13}$ The model does not suggest that the community with less littering will also experience a greater change in recycling (as drawn in Figure 9). This community could experience a smaller change in recycling.
} 
some point, however, the garbage fee would become high enough to induce some people to pay the fixed cost of recycling and thus to switch away from dumping. As a consequence, the garbage fee might decrease aggregate dumping.

We now return to the two purposes outlined in our introduction. First, we wished to lay a theoretical foundation for future empirical work. What we found is that the observed low or moderate garbage fees cannot be explained in a model where households cannot burn, dump, or litter. Therefore, we added this option to the "sdel. We described four types of households, and we aggregated individual behavior to find community demands. We found that individual behavior, and thus aggregate demands, depend upon (1) the community's distribution of household preferences for recycling, (2) the fixed costs associated with dumping. (3) the distribution of income in the community, (4) the price of recyclable materials, and (5) the presence of curbside recycling. Therefore, empirical work will require measures of those variables.

The theory also makes some specific predictions that can be tested empirically. In general, the own-price elasticity for garbage should be non-positive. The cross-price effect of the garbage fee on recycling quantities could be negative or positive at high values of the garbage fee (where it could induce people to pay the fixed cost of dumping and thus to switch out of recycling), but it should be non-negative at low values of the user fee.

Second, we wished to think about how these aggregate outcomes affect the costs and benefits to a community from the implementation of a user fee program. In particular, the heterogeneity of households implies that some communities will respond more than others. Thus a user fee is more likely to be adopted in communities with low administrative costs, large increases in recycling, and small increases in dumping. The important implication for empirical work is that the town's choice of user fee is not exogenous. 


\section{References}

Copeland, Brian R., "International Trade in Waste Products in the Presence of Illegal Disposal," Journal of Environmental Economics and Management 20 (1991): 143-62.

Dinan, Terry M., "Economic Efficiency Effects of Alternate Policies for Reducing Waste Disposal," Joumal of Environmental Economics and Management 25 (1993): 242-56.

Dobbs, Ian M., "Litter and Waste Manageme! : Disposal Taxes versus User Charges," Canadian Journal of Economics 24 (1991): 221-7.

Fullerton, Don and Kinnaman, Thomas C., "Garbage, Recycling, and Illicit Burning or Dumping," Journal of Environmental Economics and Management (forthcoming).

Jenkins, Robin, "Municipal Demand for Solid Waste Disposal Services: The Impact of User Fees," mimeo, University of Maryland (1991).

Kennedy, Peter W., and Laplante, Benoit, "Municipal Solid Waste Management: The Optimal Pricing of Garbage and Recyclables Collection," mimeo, World Bank (1994).

Morris Glenn E. and Holthausen, D. M., "The Economics of Household Solid Waste Generation and Disposal," Journal of Environmental Economics and Management 26 (1994).

Repetto, Robert, Dower, Roger C., Jenkins, Robin, and Geoghegan, Jacqueline, Green Fees: How a Tax Shift Can Work for the Environment and the Economy, Washington DC: World Resource Institute (1992).

Skumatz, Lisa A., "Variable Rates for Municipal Solid Waste: Implementation Experience, Economics, and Legislation," Policy Study No. 160, Reason Foundation (1993)

Sigman, Hillary, "A Comparison of Public Policies for Lead Recycling," mimeo, UCLA Department of Economics (1991).

Sullivan, Arthur M., "Policy Options for Toxic Disposal: Laissez-faire, Subsidization, and Enforcement," Journal of Environmental Economics and Management 14 (1987): 58-71.

Wertz, Kenneth L., "Economic Factors Influencing Households' Production of Refuse," Journal of Environmental Economics and Management 2 (1976): 263-72. 
</ref_section> 
TABLE 1

A Summary of the Four Categories of Households

\begin{tabular}{|c|c|c|c|c|}
\hline \multirow[b]{2}{*}{ Category } & \multirow[b]{2}{*}{ Feature } & \multirow[b]{2}{*}{ Value of $\rho$} & When $t^{t}=0$ & \multirow{2}{*}{$\begin{array}{l}\text { Values of } t^{z} \text { that } \\
\text { encourage participation } \\
\text { ir. turbside recycling }\end{array}$} \\
\hline & & & Curbside Recycling? & \\
\hline 1 & $\begin{array}{l}\text { Never participates in the curbside } \\
\text { recycling program. }\end{array}$ & $\rho>\overline{r^{2}}$ & No & Vone \\
\hline 2 & $\begin{array}{l}\text { Litters materials collected for recycling } \\
\text { at high values of } \varepsilon^{\varepsilon} \text {. }\end{array}$ & $\delta \mathrm{p}^{4}<\rho<\overline{\mathrm{t}^{3}}$ & No & $\rho<t^{b}<\overline{t^{\theta}}$ \\
\hline 3 & $\begin{array}{l}\text { Participates in curbside recycling for all } \\
\text { values of the user fee greater than } \rho \text {. }\end{array}$ & $0<\rho<\delta p^{k}$ & No & $\rho<t^{2}$ \\
\hline 4 & $\begin{array}{l}\text { Participates in curbside recycling for all } \\
\text { values of the user fee. }\end{array}$ & $\rho<0$ & Yes & All \\
\hline
\end{tabular}




\section{FIGURE 1}

Household Disposal Choice

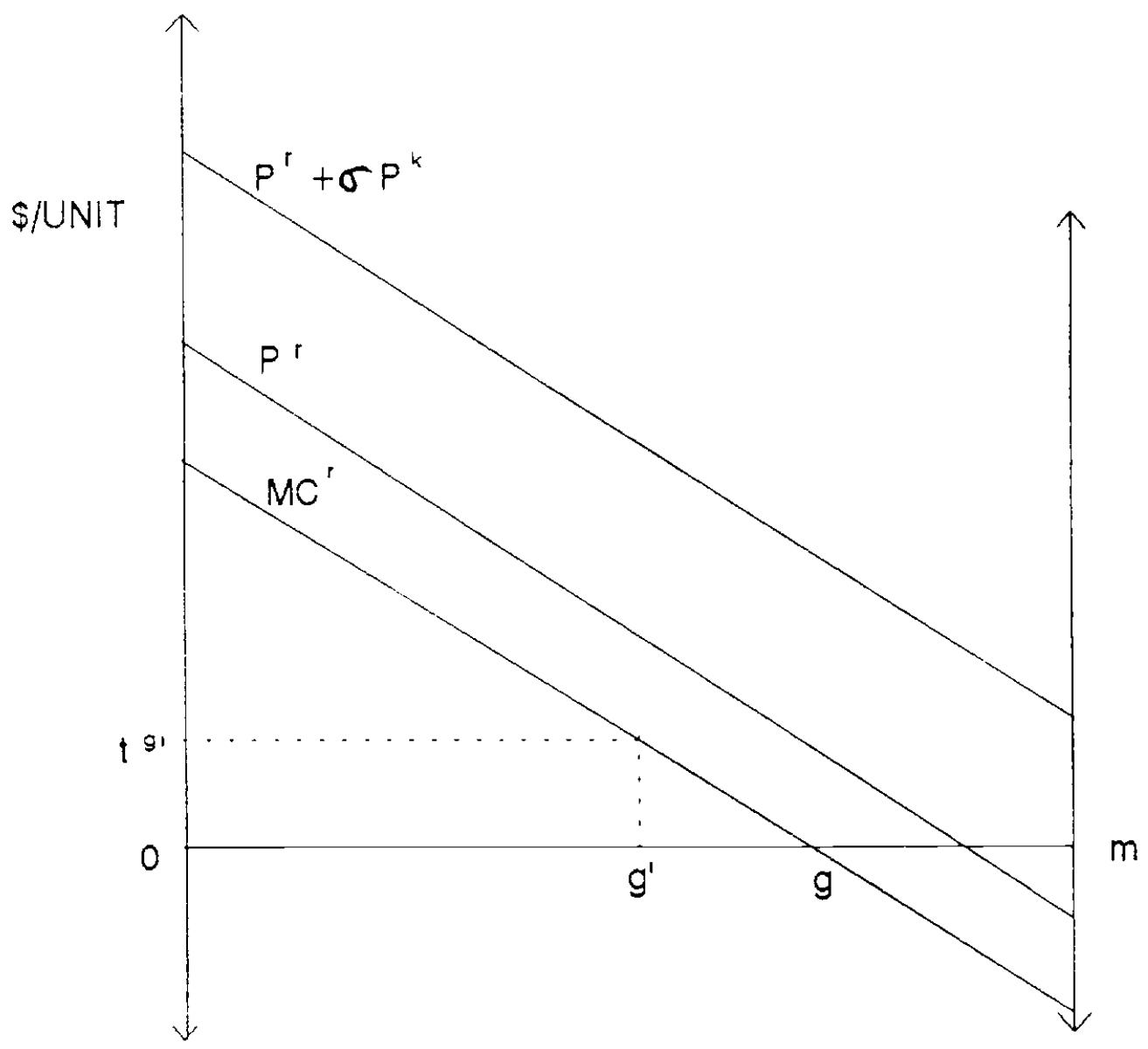


FIGURE 2

A Curbside Recycling Program

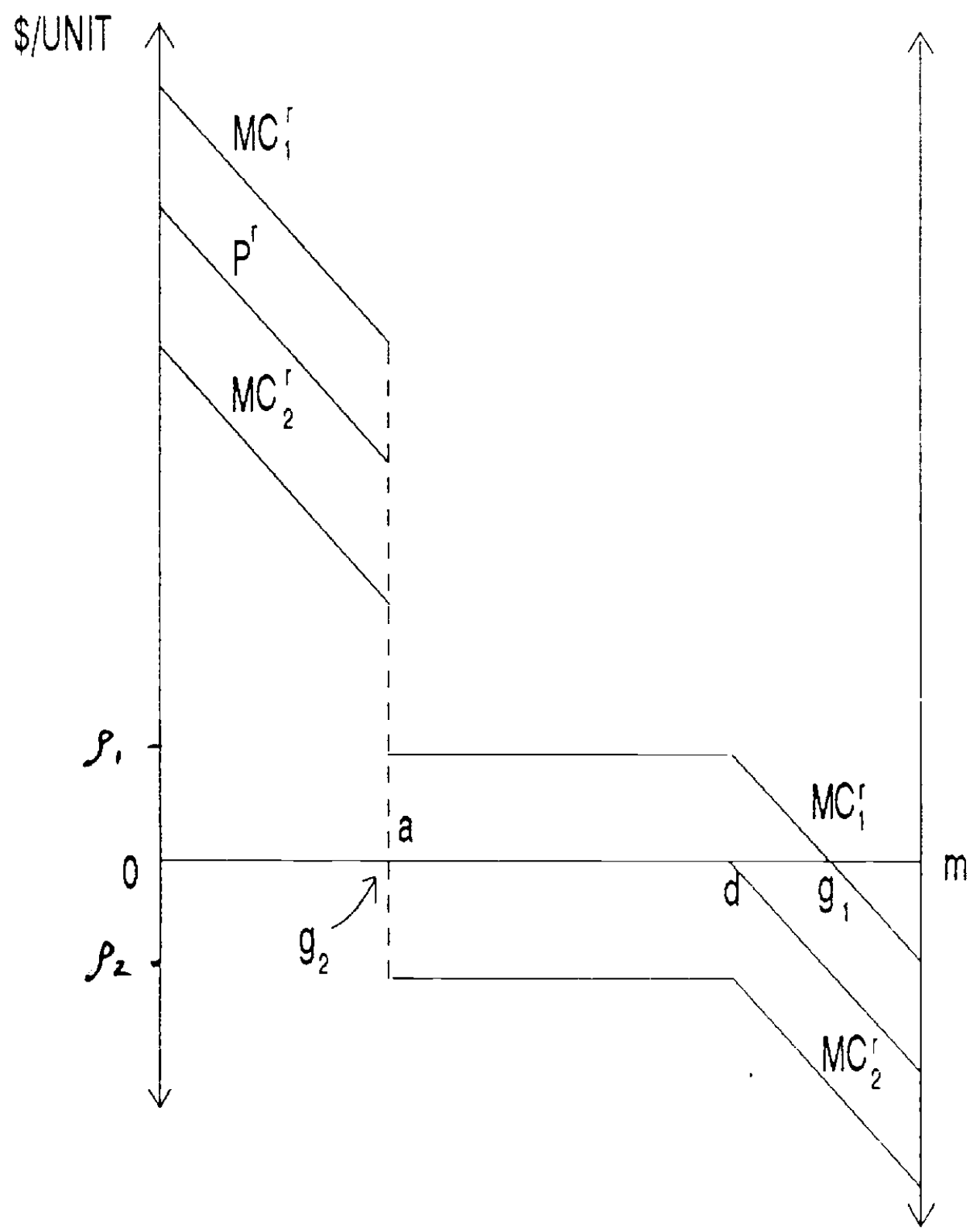


FIGURE 3

Aggregate Behavior

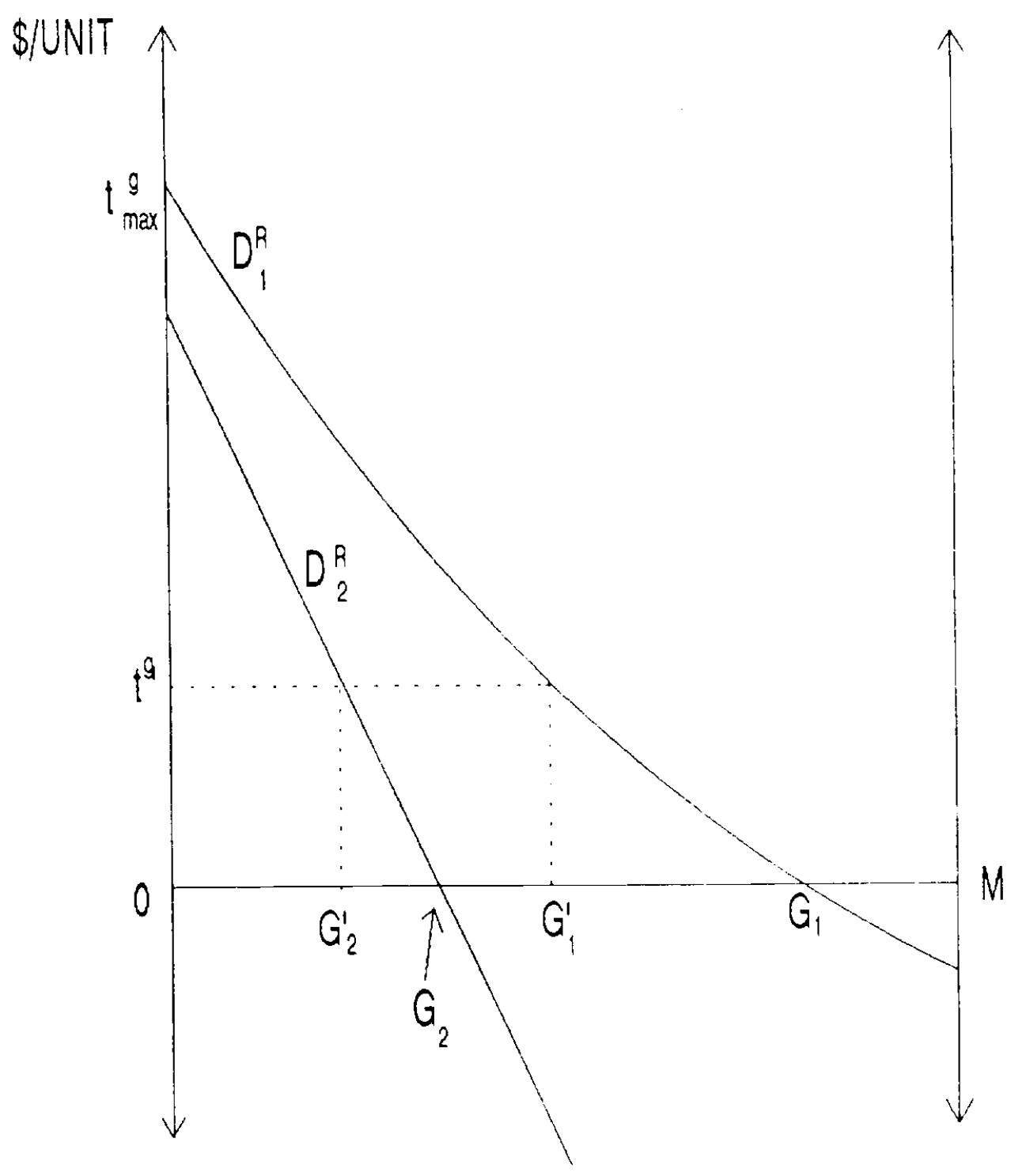



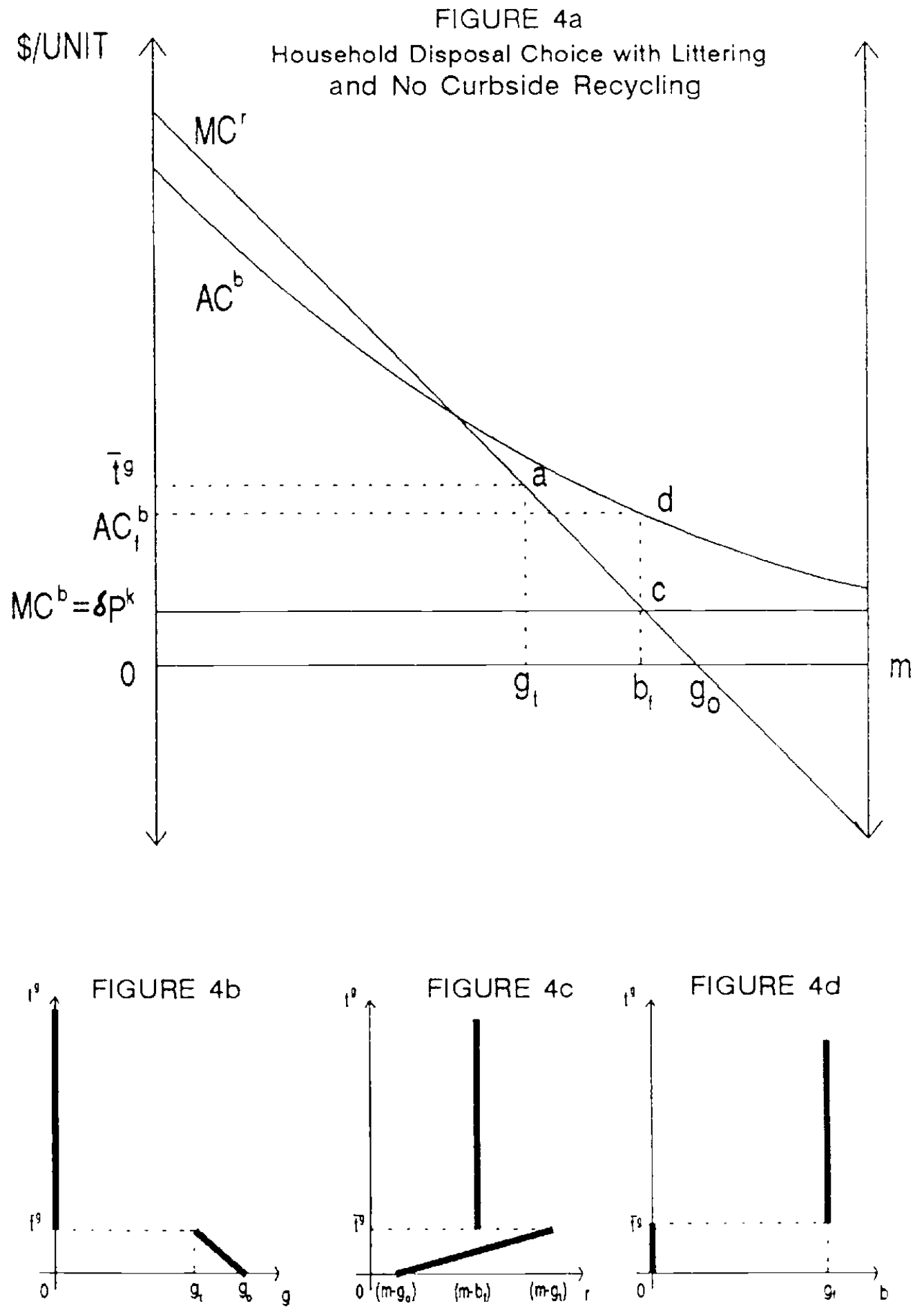
FIGURE $5 \mathrm{a}$

Category 1 Households

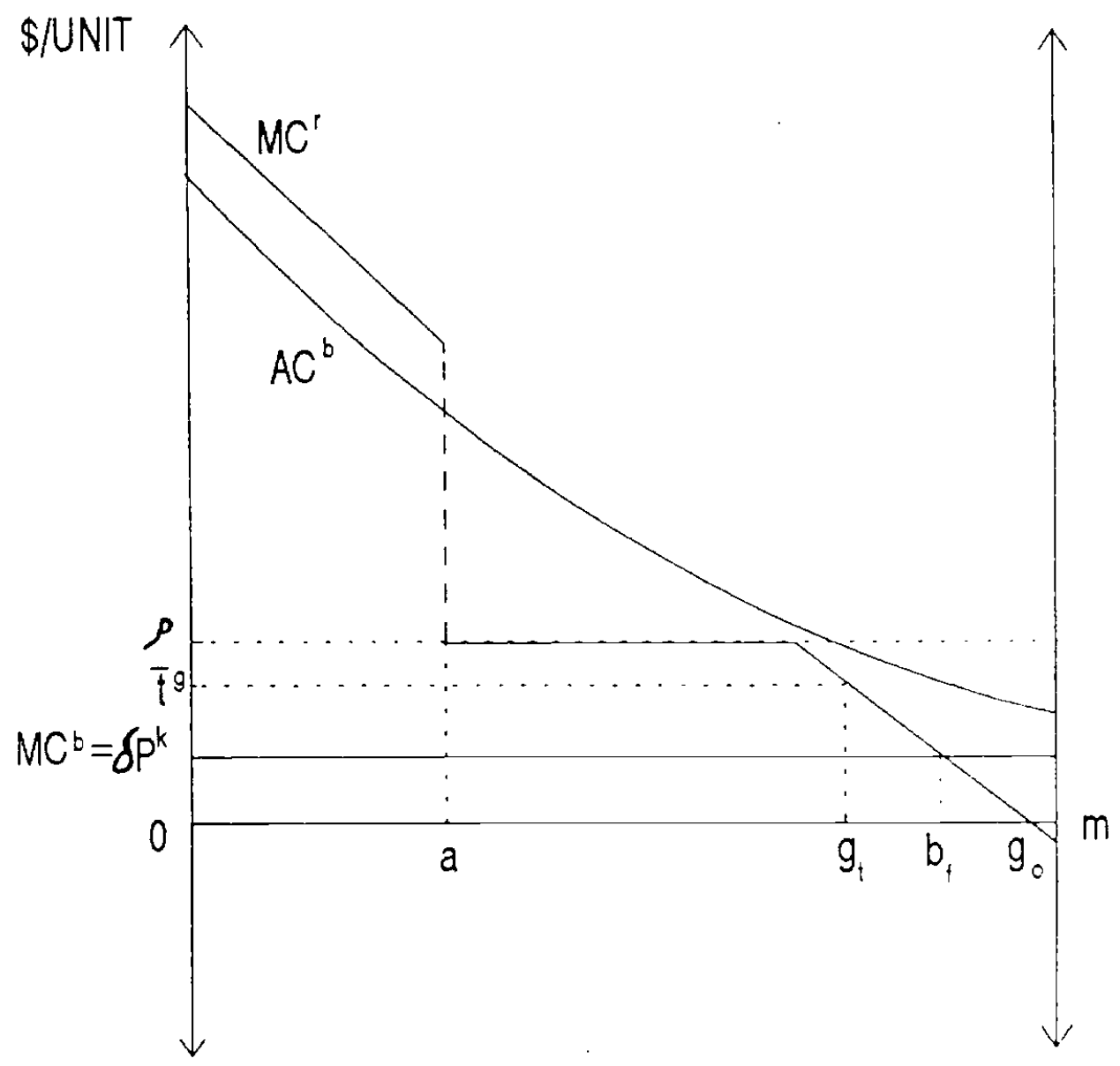

FIGURE $5 b$

FIGURE 5c

FIGURE 5d
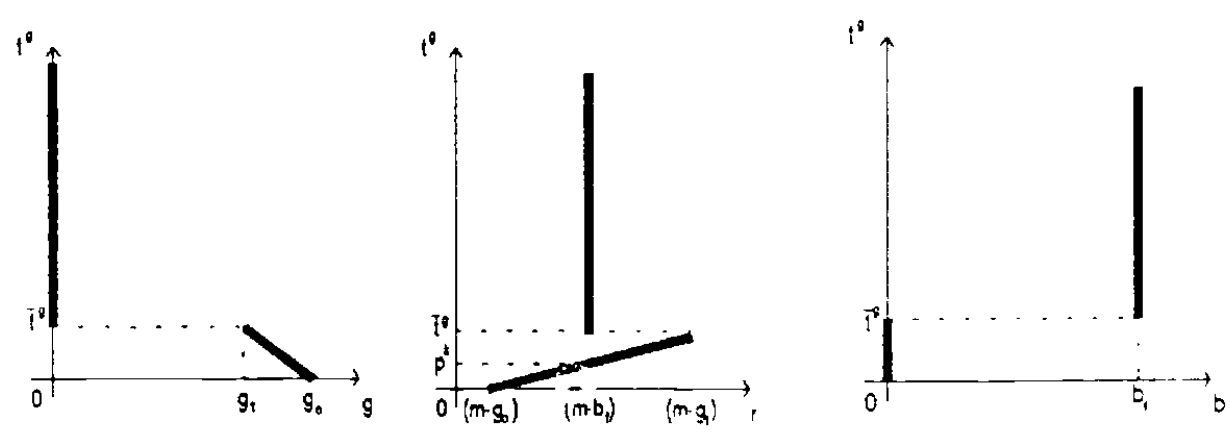
FIGURE $6 a$
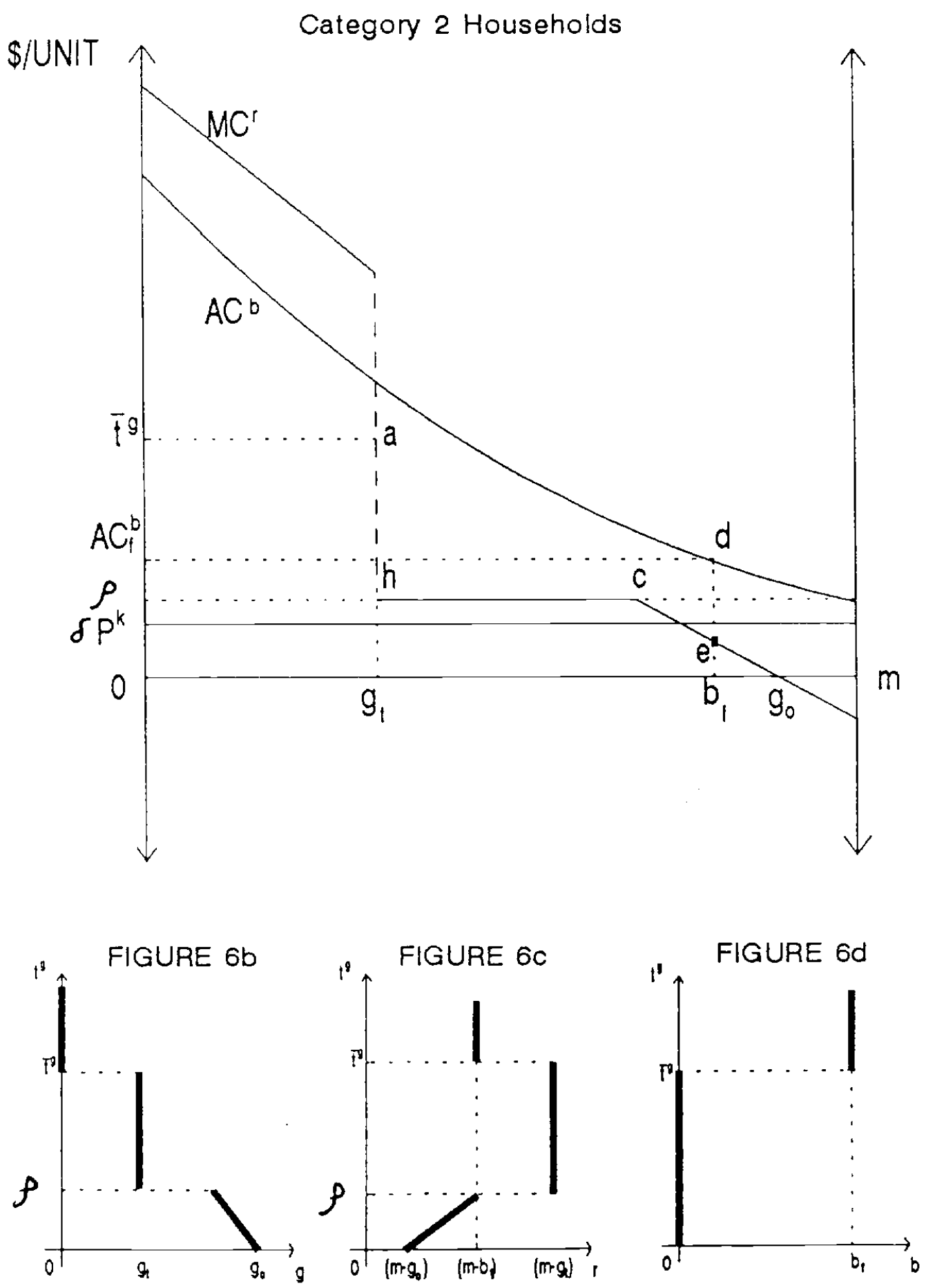
FIGURE 7a
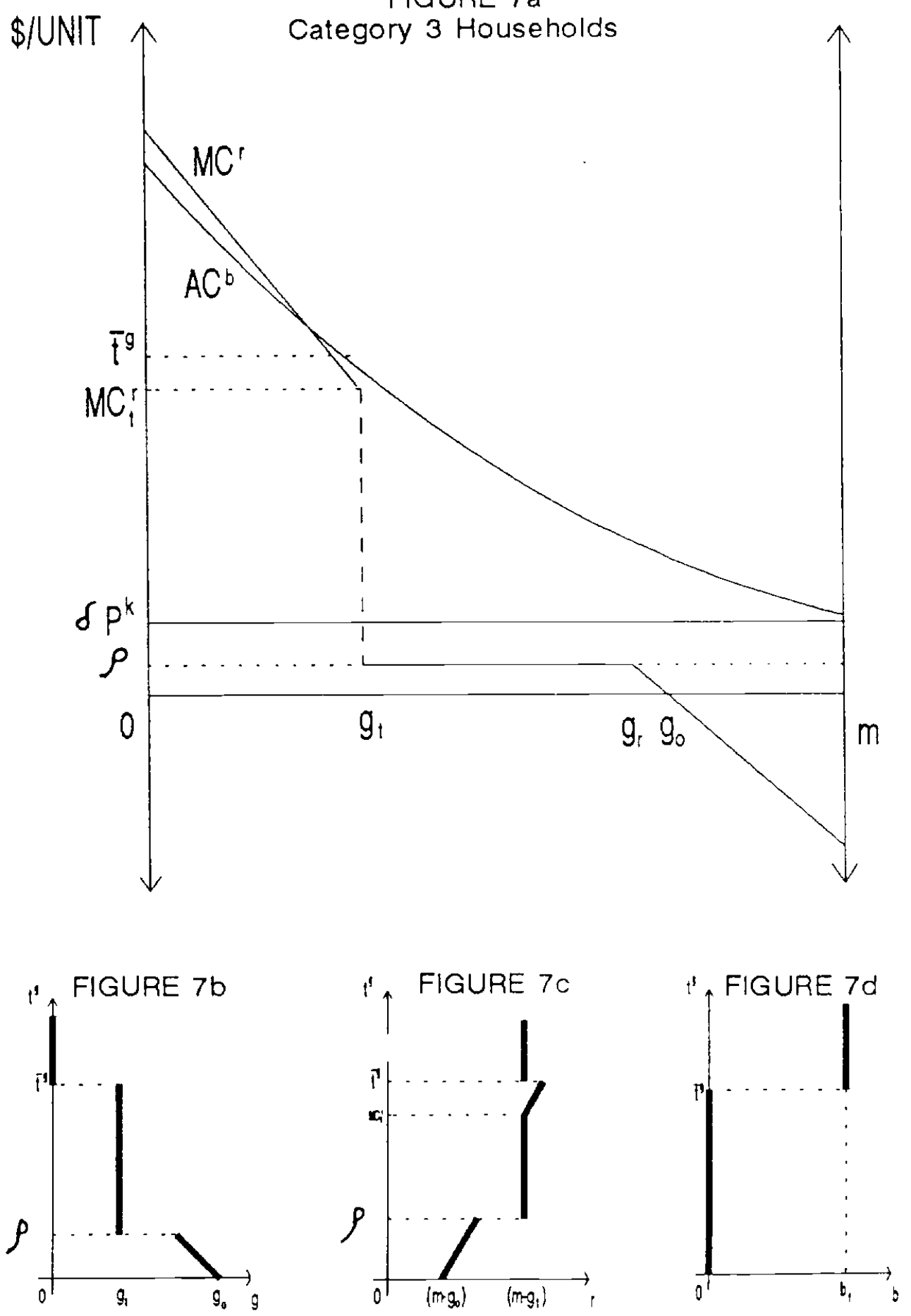
FIGURE $8 \mathrm{a}$
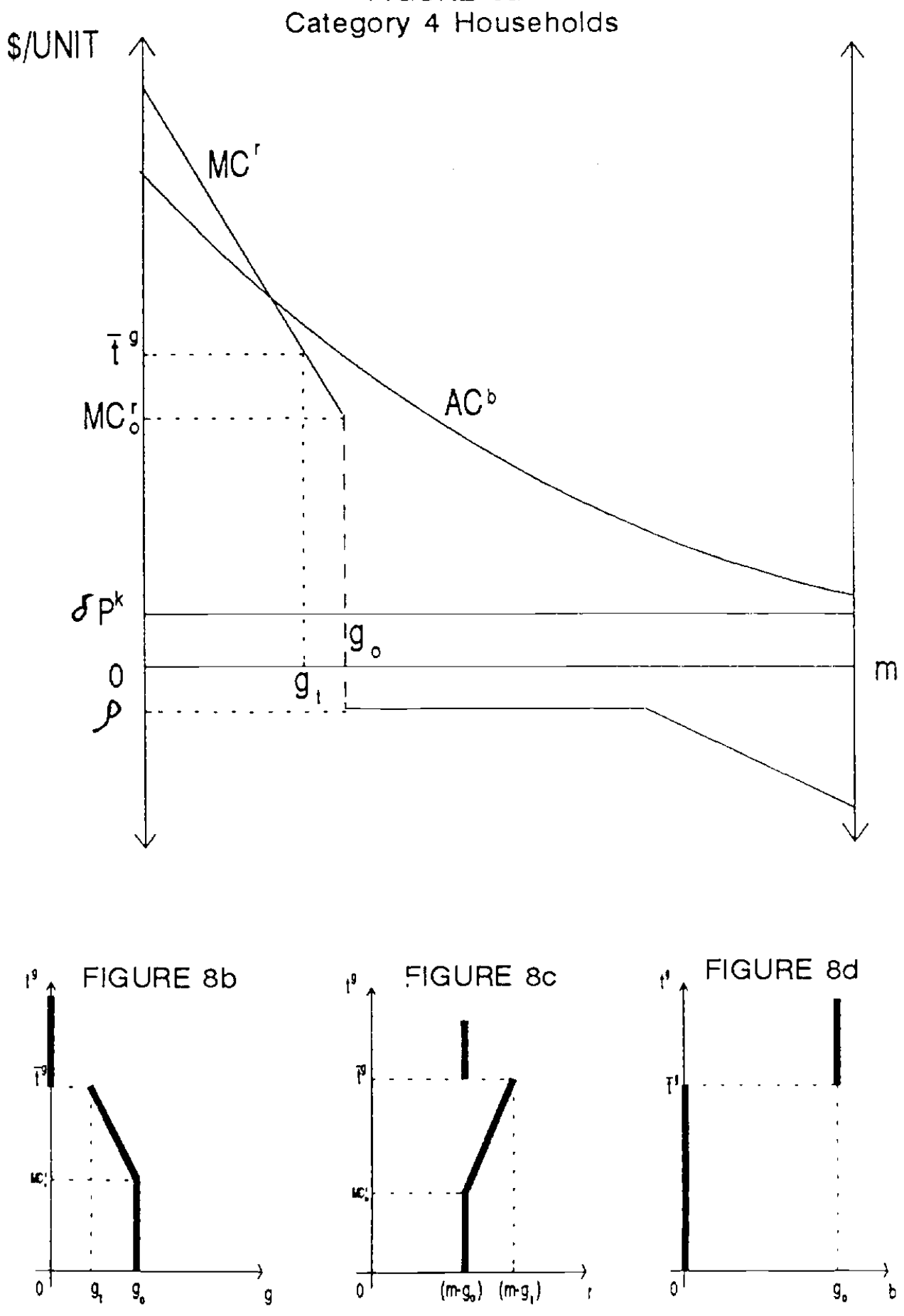
FIGURE 9

Aggregate Behavior With Littering

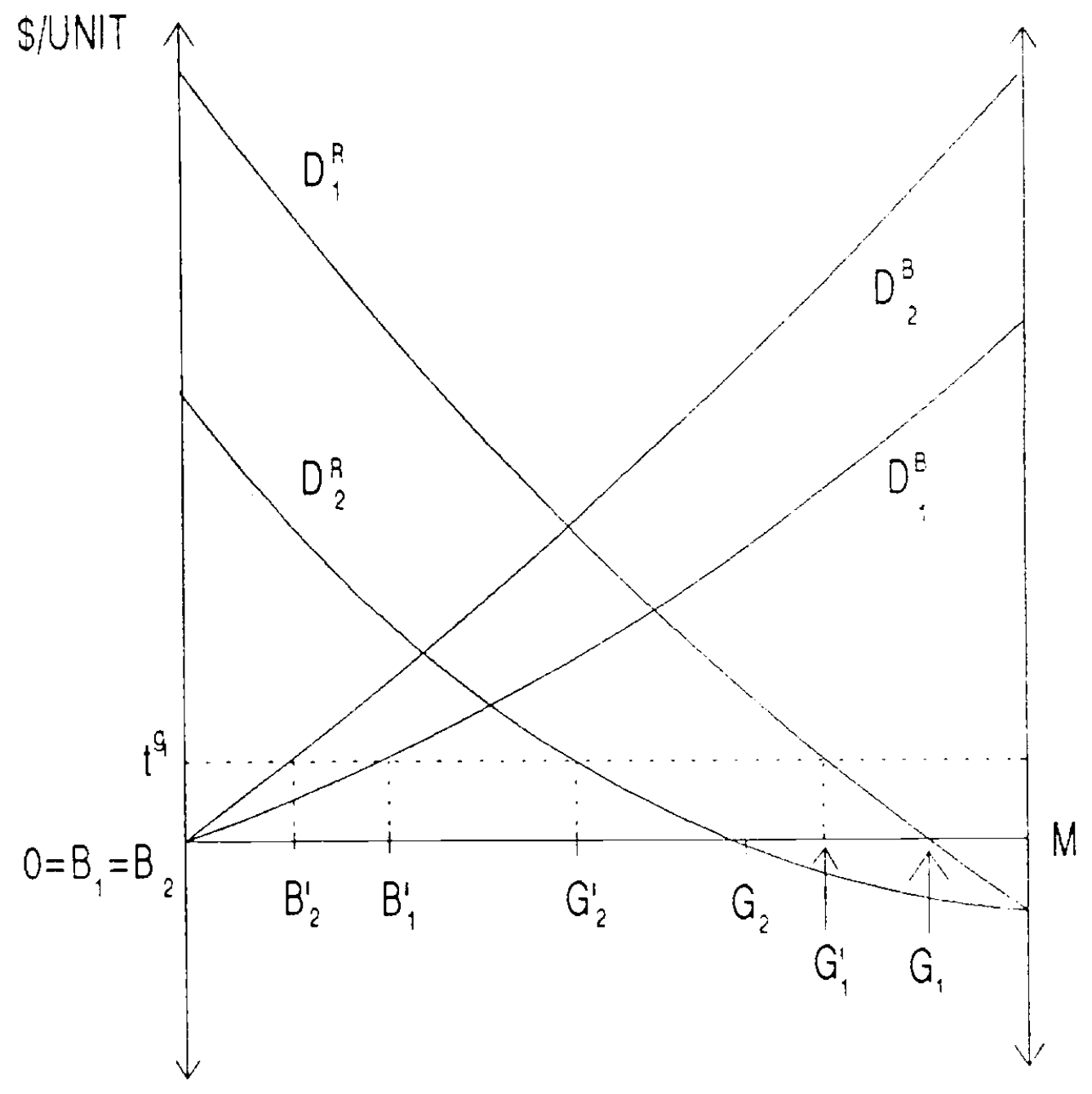

